\title{
SEGURANCCA CONSTRUTIVA E ASPECTOS DE RESSOCIALIZAĈAO: UM OLHAR DA ENGENHARIA CIVIL NO CONTEXTO DAS MEDIDAS SOCIOEDUCATIVAS
}

\author{
CONSTRUCTIVE SECURITY AND RESOCIALIZATION \\ ASPECTS: A CIVIL ENGINEERING VIEW ON THE \\ CONTEXT OF SOCIO-EDUCATIONAL MEASURES
}

Eunice Maria Nazarethe Nonato* Nádia Maria Jorge Medeiros** Edmarcius Carvalho Novaes*** Raíssa Kelly Ferreira da Silva****

Resumo: A pesquisa tem por escopo abordar a importância da segurança construtiva nas edificações de unidades socioeducativas, refletindo sobre as contribuições sociais das práticas do Engenheiro Civil diante da temática. As considerações apresentadas têm como referência o projeto de pesquisa e extensão "Juventude Educação e Direito: uma ação de intervenção em um centro socioeducativo", da Universidade Vale do Rio Doce (NONATO, 2014), cujo objetivo é contribuir no processo socioeducativo e de ressocialização de jovens em cumprimento da medida socioeducativa de privação de liberdade no Centro Socioeducativo São Francisco de Assis, em Governador Valadares - MG. As reflexões elaboradas são respaldadas em documentos técnicos referentes a essas unidades (SINASE, 2006), em concepções da Engenharia (TELLES, 1999) e no aporte teórico das contribuições de Michel Foucault (1999), para se pensar sobre as relações de poder no espaço prisional. Conclui-se que há uma necessidade de conferir uma maior importância ao espaço físico das unidades de atendimento socioeducativo.

Palavras chave: Segurança construtiva; engenharia civil; medidas socioeducativas; ressocialização.

\begin{abstract}
The research aims at addressing the importance of constructive safety in the buildings of Socio-educational Units, reflecting upon the social contributions of the Civil Engineer to the subject. The considerations presented are based on the research and extension Project Youth Education and Law: an intervention action in a socio-educational center, from the University Vale do Rio Doce - (NONATO, 2014), whose objective is to contribute to the socio-educational process and the resocialization of young people in compliance with socioeducational measures of deprivation of freedom at the São Francisco de Assis SocioEducational Center in Governador Valadares - MG. The reflections put forward are supported by technical documents referring to the Units (SINASE, 2006), Engineering conceptions (TELLES, 1999) and the Michel Foucault's (1999) theoretical contributions to think about power relations in the prison space and the conclusion points out that it is necessary to give greater concern to the space of Socio-educational Assistance Units.
\end{abstract}

Keywords: Constructive safety; civil engineering; social-educational measures; resocialization. 


\section{Introdução}

Este estudo tem por objetivo abordar a importância da segurança construtiva nas edificações de Unidades Socioeducativas, refletindo sobre a contribuição social do Engenheiro Civil diante da temática. No contexto socioeducativo, compreende-se que a segurança construtiva da edificação é de fundamental importância para assegurar o bem-estar e a proteção dos jovens acautelados, agentes de segurança, equipe técnica e de apoio.

Saber escolher os materiais a serem empregados na construção e determinar a resistência à abrasão do concreto, por exemplo, são fatores que influenciarão diretamente nos aspectos construtivos e de estabilidade dessas construções, consequentemente, no cumprimento da medida de internação de forma eficaz e segura.

As considerações iniciais apresentadas neste texto têm como referência o projeto de pesquisa e extensão da Universidade Vale do Rio Doce (UNIVALE), intitulado "Juventude Educação e Direito: uma ação de intervenção em um centro socioeducativo" (NONATO, 2014), que contou com o apoio financeiro da Fundação de Amparo à Pesquisa de Minas Gerais (FAPEMIG).

Trata-se da indissociabilidade entre pesquisa e extensão, uma vez que o referido projeto visa contribuir para a melhoria do processo educativo e de ressocialização de jovens autores de atos infracionais, em cumprimento à medida socioeducativa de internação na unidade de atendimento na cidade de Governador Valadares - MG.

O caráter de pesquisa e extensão do projeto, vinculado ao Núcleo Interdisciplinar de Educação, Saúde e Direitos - NIESD, da Universidade Vale do Rio Doce e certificado pelo Diretório dos Grupos de Pesquisa no Brasil/ CNPq, permite problematizar, enquanto objeto de pesquisa, os processos educativos a partir da vivência do acautelamento e de seus reflexos na formação educativa dos jovens autores de atos infracionais em privação de liberdade; os aspectos de saúde que são afetados e/ou agravados em decorrência da medida de internação também são considerados.

Atrelam-se a essa perspectiva as discussões afetas ao campo legal, haja vista que o processo de ressocialização, para além do cumprimento de decisão judicial face ao cometimento de atos infracionais, visa oportunizar ao jovem uma vivência capaz de (res)significar sua relação com o contexto da criminalidade, possibilitando a construção de projetos de futuro.

Os resultados já obtidos pelo projeto caminham para a produção de dissertações de Mestrado no Programa em Gestão Integrada do Território ofertado pela Universidade Vale do Rio Doce, e para realização e apresentação de trabalhos simples (resumos) e completos para seminários e congressos internacionais e nacionais, em diversos campos do conhecimento, uma vez que os alunos de graduação que participam do projeto como bolsistas de iniciação científica são oriundos de diversos cursos: pedagogia, direito, psicologia, arquitetura e urbanismo, engenharia civil, jornalismo, entre outros.

Pode-se concluir que tal programa de pesquisa e extensão favorece a relação universitária com a comunidade, já que colabora acadêmica e socialmente com o sistema socioeducativo, ao possibilitar aos jovens autores de atos infracionais momentos de formação sobre seus direitos relativos à educação e à saúde, além de favorecer a construção de projetos futuros por meio da continuidade dos estudos no contexto universitário para alguns dos jovens que participam das oficinas que compõem o componente de extensão.

\section{Método}

Este trabalho se configura metodologicamente como uma pesquisa de cunho qualitativo, a partir de procedimentos metodológicos de realização de revisão bibliográfica sobre o acautelamento, sociologia das juventudes e segurança construtiva. O estudo parte também da pesquisa de campo - com registros em diários de vivências durante as oficinas socioeducativas que se configuram como prática extensionista universitária - e de visitas técnicas às locações internas da unidade de atendimento (objeto de análise) para a observação do espaço e realização de diálogos com a diretoria responsável pela instituição, especificamente sobre aspectos do projeto arquitetônico e estrutural da Unidade Socioeducativa.

O Centro Socioeducativo São Francisco de Assis recebe jovens com idades entre 14 e 21 anos $^{1}$, cuja escolarização varia entre o Ensino Fundamental e o Ensino Médio. Atualmente, segundo dados do Plano Decenal de Atendimento Socioeducativo de Governador Valadares (2016), o centro acolhe em torno de 123 (cento e vinte e três) acautelados ${ }^{2}$, todos do gênero masculino, com possibilidade de mudança desse número a todo instante, uma vez que o espaço atende à demanda da cidade e de outros municípios próximos. Porém, tal acautelamento com superlotação colide com a Resolução $\mathrm{n}^{\circ}$ 46/96 do Conselho Nacional dos Direitos da Criança e do Adolescente CONANDA e com o Sistema Nacional de Atendimento Socioeducativo - SINASE (2006), que estabelecem um atendimento não superior a 40 (quarenta) jovens por unidade.

Apesar de a superlotação em espaços de privação de liberdade ocorrer de forma corriqueira (CNMP, 2013), esse fato não pode ser desconsiderado 
ou tratado sem sua devida importância: além de não possibilitar as condições mínimas de habitabilidade necessárias ao processo de ressocialização, isso ainda pode acarretar grandes aglomerações, e, consequentemente, a destruição do patrimônio público, rebeliões e fugas, além de criar situações que viabilizem riscos à vida, no caso de rixas ou descontentamentos entre os acautelados ou até mesmo com os agentes e demais profissionais da unidade.

Entende-se que, ao projetar a parte estrutural de uma edificação, o engenheiro precisa questionar aspectos construtivos relacionados à segurança, tais como: o tempo de permanência na edificação, a periodicidade de sua manutenção, elementos estruturais empregados para a situação, número de pessoas que irão utilizá-la, dentre outros fatores que irão influenciar em sua sustentabilidade, o que, de acordo com as orientações do Ministério do Meio Ambiente (BRASIL, 2016), além de priorizar a redução e a otimização do uso de materiais, propicia ainda a qualidade do meio ambiente construído.

Assim, há que se refletir sobre as condições das construções com vistas à ressocialização, ultrapassando perspectivas simplistas que sugerem a ressocialização mediante punição, pois também é papel do engenheiro refletir sobre a importância do cumprimento da medida socioeducativa como possibilidade de ressocialização dos jovens acautelados, no período da privação de liberdade.

Pensar em edificações seguras, prevenindo eventuais desvios de utilização dos materiais estruturais da edificação para criação de objetos perigosos por parte dos jovens privados de liberdade, por exemplo, é uma forma de o engenheiro cumprir com seu papel social, trabalhando no desenvolvimento de materiais e modelos estruturais que garantam a segurança e a qualidade de vida dos usuários do equipamento público.

Diante disso, é objetivo do presente estudo abordar a importância da segurança construtiva nas edificações de unidades socioeducativas, refletindo sobre a contribuição social do Engenheiro Civil diante da temática, tendo como foco a experiência vivenciada no projeto de extensão citado, o que nos possibilitou a incursão no campo de pesquisa, para além das práticas extensionistas do projeto.

As reflexões aqui propostas são respaldadas em documentos técnicos referentes aos centros socioeducativos, em diálogo com conceitos da Engenharia Civil no que tange à construção civil (TELLES, 1999). A partir das contribuições de Michel Foucault (1999), também foi feita uma discussão acerca do espaço prisional.

\section{Resultados técnicos e discussão da experiência}

A experiência de pesquisa no contexto da privação de liberdade de jovens autores de atos infracionais fomentou inquietações sobre a segurança construtiva de unidades socioeducativas.

A palavra segurança em si, originada do latim securitas, implica em reduzir ou exterminar qualquer forma de risco à vida, ou seja, remete-se à ideia de estabilidade e firmeza, relacionando-se ao estado de "estar seguro". Em outras palavras, em uma definição mais simples, a segurança implica em evitar que o mal aconteça; trata-se da ausência de perigos, pois se pauta por algo previsível e a certeza quanto ao que virá (FERREIRA, 2000).

$\mathrm{Na}$ construção civil, o termo pode e deve ser empregado em diversos momentos: na elaboração do projeto arquitetônico e estrutural, na execução de uma edificação ou na atenção quanto à segurança do trabalhador. Assim, a segurança construtiva deve ser aplicada, na prática profissional de engenheiros civis, para a elaboração e execução de projetos arquitetônicos e estruturais, visando resguardar todo o planejamento proposto para uma determinada construção.

Uma etapa do projeto estrutural de uma edificação é pensar no dimensionamento de lajes, pilares e vigas, levando em consideração quais serão suas utilidades na edificação, quem serão os usuários e o que irá lhe sobrepor. Ainda devem ser pensados e aplicados, para garantir a segurança na construção, alguns fatores, tais como: definir a resistência à compressão para o tipo de obra; os materiais a serem empregados; prever os períodos de manutenção, além de outros fatores que implicarão num melhor sistema construtivo para a edificação, como as características e propriedades do concreto a ser utilizado.

Contudo, essa segurança construtiva não se aplica somente em relação aos aspectos físicos de uma edificação, uma vez que é preciso considerar todo o contexto social no qual a obra irá se inserir. No contexto das medidas socioeducativas, o próprio SINASE (2006), em relação à estrutura física das Unidades de Atendimento Socioeducativo como um todo, determina que tais unidades devam "respeitar as exigências de conforto ambiental, de ergonomia, de volumetria, de humanização e de segurança" (2006, p. $67)$.

Dessa forma, o engenheiro, na qualidade de gestor da obra, cumpre seu papel de profissional ciente de suas responsabilidades sociais, ao se preocupar com o bem-estar que a edificação proporcionará para aqueles envolvidos no sistema, sejam técnicos, agentes ou os próprios adolescentes e jovens acautelados. Esse bem-estar, segundo Ferreira (2000, p. 94), além de se relacionar com o "(...) estado de perfeita satisfação física ou moral, conforto (...)", também diz respeito à sensação de se sentir seguro. 
Diante disso, as inovações e tecnologias empregadas nos projetos de Engenharia Civil podem garantir maior estabilidade da edificação e, direta ou indiretamente, influenciam na sensação de segurança. A segurança construtiva, portanto, implica em uma responsabilidade quanto à construção civil: deve-se cuidar de todos os fatores que envolvam projeto execução e manutenção de obras-, preocupando-se mais com os quesitos físicos e estruturais, por garantirem solidez à edificação, mas não se esquecendo dos fatores sociais e da condição humana, como a importância de favorecer o bem-estar e a sensação de segurança.

Já como resultados dessa experiência vivenciada com o projeto de pesquisa e extensão (NONATO, 2014), por meio de visitas, observações e relatos orais feitos pela diretoria e técnicos responsáveis pelo Centro Socioeducativo São Francisco de Assis, foi possível constatar que, em relação aos aspectos físicos das edificações existentes no espaço, a unidade segue o modelo proposto pelo SINASE (2006). Entretanto, há alguns fatores importantes para a vida útil da estrutura que são pouco considerados, como a importância da fiscalização e manutenção.

De acordo com a diretoria da unidade, o engenheiro responsável pela obra reside na capital mineira, Belo Horizonte - $\mathrm{MG}^{3}$. Assim, a fiscalização da estrutura da unidade socioeducativa fica a cargo dos próprios funcionários e agentes do local que, sem nenhuma formação técnica voltada à área, realizam pequenos consertos.

Ainda, a verba para manutenção, que deveria ser repassada mensalmente, além de insuficiente, chega de forma trimestral; muitas vezes, ela é completamente utilizada para o reparo de descargas sanitárias. Como resultado dessa escassez de recursos, é possível verificar que a pintura de todo o local se encontra deteriorada, as paredes estão sujas e já sem cor, isso sem contar que tantos outros consertos não são concretizados e nem há previsão de quando acontecerão.

De acordo com a Norma Brasileira Regulamentadora (NBR 5674) da Associação Brasileira de Normas Técnicas - ABNT (1999), as edificações são denominadas como "suporte físico para a realização direta ou indireta de todas atividades produtivas, e possuem, portanto, um valor social fundamental" (1999, p. 1). Dessa maneira, são construídas para atender a uma determinada demanda durante muito tempo; durante toda a sua vida útil, devem estar em condições aceitáveis de uso.

Entretanto, por ser uma obra durável, isso não quer dizer que a edificação não necessite de manutenção. Ao contrário, é por meio da manutenção que se garante o seu funcionamento de acordo com o determinado em um projeto, no período préestabelecido. Ainda segundo a referida norma (ABNT, 1999),
(...) a omissão em relação à necessária atenção para a manutenção das edificações pode ser constatada nos frequentes casos de edificações retiradas de serviço muito antes de cumprida a sua vida útil projetada (pontes, viadutos, escolas), causando muitos transtornos aos seus usuários e um sobrecusto em intensivos serviços de recuperação ou construção de novas edificações. Seguramente, pior é a obrigatória tolerância, por falta de alternativas, ao uso de edificações cujo desempenho atingiu níveis inferiores ao mínimo recomendável para um uso saudável, higiênico ou seguro. Tudo isto possui um custo social que não é contabilizado, mas se reflete na qualidade de vida das pessoas. (ABNT, 1999, p. 2).

Em uma unidade socioeducativa, as regras gerais de manutenção e demais cuidados, quanto à engenharia e estrutura empregadas, não podem ser desprezadas. Trata-se de um ambiente de ressocialização, por isso não se pode esquecer principalmente do quesito 'segurança', tanto no sentido de assegurar a vida dos envolvidos no sistema quanto da segurança e reforço estrutural da construção para garantir sua solidez.

Ao pensar sobre segurança em relação à vida e à estrutura da edificação, é necessário mencionar a falta de salubridade nos alojamentos dos acautelados. Tratase do aspecto que mais chama a atenção, uma vez que se constitui como um retângulo pequeno, sem portas e janelas, apenas grades, não possuindo iluminação e ventilação naturais suficientes. Geralmente com lotação acima do máximo permitido, esse espaço úmido e sem manutenção torna-se propício ao surgimento de fungos e bactérias nas paredes e cantos da estrutura, o que pode acarretar danos à saúde dos alojados.

Além dessas situações citadas, atualmente, o Centro Socioeducativo São Francisco de Assis está superlotado, em número muito superior ao estabelecido pela SINASE (2006). Essa situação traz diversos incômodos, tanto para os próprios jovens do local quanto para os agentes e técnicos, uma vez que favorece a possibilidade de rebeliões, fugas $\mathrm{e}$ consequente destruição da estrutura da unidade. Assim, todos esses aspectos, como falta de fiscalização e manutenção da edificação, insalubridade nos ambientes e superlotação, entre outros, afetam a segurança construtiva da Unidade, influenciando em sua vida útil determinada em projeto.

Outro resultado da pesquisa se relaciona à função social do engenheiro no contexto das medidas socioeducativas, entendendo sua responsabilidade com a segurança da edificação, garantindo a ideia da ressocialização proposta pelo ordenamento jurídico brasileiro. Nesse sentido, cabe ao engenheiro conhecer de forma aprofundada os modelos arquitetônicos de unidades de atendimento socioeducativo e, ao atuar nesse contexto, buscar o equilíbrio entre a segurança e ressocialização, condição básica para qualquer estabelecimento que se proponha, direta ou indiretamente, cercear a liberdade da pessoa, como os presídios e as clínicas de reabilitação. 
O SINASE (2006, p. 69), ao direcionar sobre a concepção arquitetônica dessas unidades, deixa claro que o objetivo é alcançar a ressocialização. Contudo, não se pode desvincular a noção de que se trata de um ambiente de privação de liberdade e, consequentemente, de punição. Nesse sentido, o mesmo documento ainda aponta que

(...) a concepção arquitetônica deve integrar também os demais espaços para o desenvolvimento de atividades coletivas, na perspectiva de criar ambientes que possibilitem a prática de uma vivência com características de moradia sem, no entanto, desconsiderar que é uma Unidade de atendimento de privação de liberdade. (SINASE, 2006, p. 69).

Dessa forma, trata-se de uma situação contraditória que, de acordo com Silva et al. (2016, p. $5)$, “(...) ao mesmo tempo em que se pensa em ressocializar mediante a privação da liberdade, o próprio ato de "resguardar" e vigiar impede a efetiva socialização do sujeito". Assim, reflete-se sobre a função social do engenheiro ao pensar a construção dessas unidades, pois, ao se atentar para o quesito segurança, como profissional ciente de suas responsabilidades para com a sociedade, deverá incorporar na construção a condição humana, como elemento vital.

De acordo com Foucault (1999), durante muito tempo, os suplícios - castigos e torturas corporais eram o meio pelo qual se fazia "justiça". Com o passar dos anos, optou-se por "uma execução que atinja a vida mais do que o corpo" (FOUCAULT, 1999, p. 15) e, nesse caso, a prisão para a privação da liberdade. Entretanto, considerando a atual situação dos espaços de privação de liberdade (penitenciárias e centros socioeducativos), além de uma punição psicológica que o encarceramento realiza no sujeito, há também um castigo físico: espaços superlotados e sem o mínimo de salubridade e condições de habitabilidade, onde os detentos e acautelados permanecem cumprindo suas sentenças e medidas, sujeitos a diversos riscos à saúde, sejam físicos ou psicológicos. Assim, "a prisão, nos seus dispositivos mais explícitos, sempre aplicou certas medidas de sofrimento físico" (FOUCAULT, 1999, p. 18) e o continua fazendo.

Todavia, tendo que ser dessa maneira e como uma "detestável solução, de que não se pode abrir mão" (FOUCAULT, 1999, p. 196), a penalização da privação de liberdade, seja no contexto prisional ou nas medidas socioeducativas, pode e deve ser repensada, a começar pelo espaço, pois este “(...) influencia as relações consigo mesmo e com o outro, uma vez que é o meio no qual ocorre a socialização" (SILVA et al., 2016, p. 3).

Sendo uma aplicação de diversos conhecimentos nas áreas científicas, econômicas, sociais e prática, a Engenharia tem como objetivo criar, construir e melhorar estruturas, materiais, processos etc., visando fornecer modelos cada vez mais eficazes e que contribuam para o desenvolvimento da sociedade em diversos setores. Telles (1999) relata sobre essa função social da engenharia, quando menciona que

[...] não é uma atividade secundária, mas uma
decorrência intrínseca da própria profissão. Tudo o que
o engenheiro faz, dentro da sua profissão, destina-se,
em última análise, a satisfazer alguma necessidade
humana, e portanto uma necessidade social [...].
(TELES, 1999, p. 116)

O Engenheiro Civil, trabalhando no contexto socioeducativo, pode colaborar para o desenvolvimento de novos sistemas estruturais que permitam, além de uma estabilidade na edificação, um conforto e bem-estar visual. Ainda, trabalhar na criação e em ensaios de materiais de qualidade e com menor custo, uma vez que um grande problema é o repasse financeiro do Estado, que é mínimo para a manutenção dessas unidades.

Diversos sistemas construtivos de rápida montagem, custo acessível e conforto ambiental estão sendo criados e utilizados em diversas obras públicas pelo país. Basta um olhar humanizado voltado à situação das unidades de atendimento socioeducativo para mudar a realidade de muitos desses espaços. Em Belo Horizonte, por exemplo, unidades educacionais públicas estão sendo construídas, com uma infraestrutura de qualidade, baixo custo de manutenção e em curto prazo (CBCA, 2015). Trata-se de uma estrutura em aço, conhecida como light steel framing que, entre outras vantagens, também possibilita uma redução de impactos ambientais causados pelo desperdício da construção civil, ainda possibilitando a utilização de drywall nas vedações internas para favorecer um clima agradável dentro dos ambientes.

Ao se pensar essa concepção de construção, é importante que os trabalhos de arquitetura e de engenharia caminhem juntos para a elaboração de novos modelos arquitetônicos, com novas formas, mais cor e conforto ambiental, sem desconsiderar a necessária solidez, segurança e vigilância que esses espaços pressupõem. Desta forma, a segurança construtiva que uma unidade socioeducativa exige é entendida como mais do que um meio pelo qual se pune e controla o sujeito, mas é preciso pensá-la para garantir a qualidade de vida do jovem acautelado dentro de um espaço, preocupando-se com sua funcionalidade, segurança, economia e estética: fatores que constituem a responsabilidade social da engenharia (TELLES, 1999).

Logo, a efetiva ressocialização em unidades socioeducativas dependerá, dentre outros fatores, da qualidade no processo de socialização. Como o espaço se configura em um importante caminho para isso, há a necessidade de se repensar suas formas num todo, afinal de contas, “(...) o pleno desenvolvimento ou não das potencialidades que caracterizam o ser humano vai 
depender da qualidade das relações sociais desse meio no qual se insere" (DAYRELL, 2003, p. 43).

\section{Considerações finais}

Diante do que foi exposto, conclui-se que há necessidade de conferir uma maior importância ao espaço físico das unidades de atendimento socioeducativo, tanto no sentido de projetar e executar quanto no de manter, pois é ele o meio pelo qual o sujeito vivencia o cumprimento da medida de privação de liberdade, tornando-se, por isso, condição básica no processo de ressocialização.

Ainda, há que se pensar, no que tange à engenharia empregada, em estruturas dinâmicas, inovadoras e que facilitem o processo de construção e/ou montagem, como também a de manutenção, colaborando para que esta possa ser realizada de forma simples e com baixo custo, uma vez que o repasse financeiro para a manutenção desses espaços de acautelamento é insuficiente para realmente mantê-los, além de não contar com mão de obra qualificada para esse fim.

$\mathrm{Na}$ experiência vivenciada no projeto de pesquisa e extensão "Juventude Educação e Direito: uma ação de intervenção em um centro socioeducativo", da Universidade Vale do Rio Doce percebeu-se que o papel da Engenharia Civil, mais do que se preocupar com o espaço e a estrutura de uma unidade socioeducativa, também é o de refletir sobre o sujeito e sua condição humana dentro de um ambiente destinado à privação da liberdade. Com isso, deve-se pensar em formas de contribuir para que esse tempo do acautelamento tenha o mínimo de conforto necessário ao processo de ressocialização, mediante a um espaço projetado e executado com esses fins.

\section{Referências bibliográficas}

ABNT, Associação Brasileira de Normas Técnicas. Norma Brasileira Regulamentadora - NBR 5674. Rio de Janeiro: ABNT, 1999.1 Disponível em: $<$ http://www.pmb.eb.mil.br/images/documentos/abnt/abnt_0 5674.pdf $>$. Acesso em: 06 dez. 2016.

BRASIL. Sistema Nacional de Atendimento Socioeducativo -SINASE: Secretaria Especial dos Direitos Humanos. Brasília: CONANDA, 2006. Disponível em: $<$ http://www.conselhodacrianca.al.gov.br/sala-deimprensa/publicacoes/sinase.pdf $>$. Acesso em: 03 nov. 2016.

CBCA, Centro Brasileiro da Construção em Aço. Light Steel Framing: aplicações do sistema construtivo. Arquitetura \& Aço, Rio de Janeiro, n. 47, set. 2016. disponível em: $<$ http://www.cbcaacobrasil.org.br/site/publicacoesrevistas.php? codDestaque $=101495>$. Acesso em: 10 jun 2017.

CNMP, Conselho Nacional do Ministério Público. Um olhar mais atento às unidades de internação $\mathrm{e}$ semiliberdade para adolescentes. Relatório da Infância e Juventude - Resolução no 67/2011. Brasília: Conselho Nacional do Ministério Público, 2013.

DAYRELL, Juarez. O jovem como sujeito social. Revista Brasileira de Educação, n. 24, p. 40-52, set/out/nov/dez de $2003 . \quad$ Disponível em: $<$ http://www.scielo.br/pdf/rbedu/n24/n24a04>. Acesso em: 22 jun. 2016.

FERREIRA, Aurélio Buarque de Holanda. Mini Aurélio: o minidicionário da língua portuguesa. 3. ed. Rio de Janeiro: Nova Fronteira, 2000.

FOUCAULT, Michel. Vigiar e Punir: nascimento da prisão. 19. ed. Petrópolis: Eđitora Vozes, 1999. 261p.

GOVERNADOR VALADARES. Plano Decenal de Atendimento às Medidas Socioeducativas de Governador Valadares. Secretaria Municipal de Assistência Social. Prefeitura Municipal de Governador Valadares. 2016.

NONATO, E. M. N. JUVENTUDE, EDUCAÇ̃̃O E DIREITO: ação de intervenção em um centro socioeducativo. Projeto de Pesquisa e Extensão. Universidade Vale do Rio Doce. 2014.

SILVA, Raissa Kely Ferreira da; COELHO, Adriana de Oliveira Leite; NONATO, Eunice Maria Nazathe. A função socializadora do espaço na medida socioeducativa. In: Colóquio Internacional Educacão e Contemporaneidade, 10, 2016. São Cristovão - SE. Anais eletrônicos... São Cristovão, 2016. p 1-11.

TELLES, Pedro C. da Silva. A função social e a responsabilidade social do Engenheiro. Revista Militar de Ciência e Tecnologia, Rio de Janeiro, v. 16, n. 2, p 116120, mai/ago 1999.

\footnotetext{
Notas

${ }^{1}$ De acordo com o ECA, "nos casos expressos em lei, aplica-se excepcionalmente este Estatuto às pessoas entre dezoito e vinte e um anos de idade" (BRASIL, 1990, p. 1).

2 Dado levantado na data de 12/08/2016, na ocasião da visita ao local.

${ }^{3}$ Dado registrado em diário de bordo.
} 